16,17

\title{
Эндоэдральные металлофуллерены с иттрием: синтез и выделение
}

\author{
(C) Г.Н. Чурилов ${ }^{1,2}$, Н.Г. Внукова ${ }^{1,2}$, Е.В. Томашевич ${ }^{3}$, А.И. Дудник ${ }^{1}$, Г.А. Глущенко ${ }^{1}$, \\ И.А. Дубинина ${ }^{1,2}$, У.Е. Гуляева ${ }^{1,2}$, Е.И. Мельникова ${ }^{2}$ \\ ${ }^{1}$ Институт фризики им. Л.В. Киренского ФИЦ КНЦ СО РАН, \\ Красноярск, Россия \\ ${ }^{2}$ Сибирский феедеральный университет, \\ Красноярск, Россия \\ ${ }^{3}$ Институт химии и химической технологии ФИЦ КНЦ СО РАН, \\ Красноярск, Россия \\ E-mail: churilov@iph.krasn.ru
}

(Поступила в Редакцию 24 октября 2016 г.

В окончательной редакции 20 января 2017 г.)

\begin{abstract}
Представлены результаты синтеза эндоэдральных металлофуллеренов с иттрием в дуговом высокочастотном разряде в потоке гелия при введении $\mathrm{Y}_{2} \mathrm{O}_{3}$. Показано, что образование металлофуллеренов зависит от давления гелия в камере, однако эта зависимость не может быть объяснена в рамках модели образования обычных фуллеренов, не содержащих внутри молекулы атома-гостя. Приведены результаты получения $\mathrm{Y} @ \mathrm{C}_{82}$, выделение которого осуществлялось как пиридином, так и дисульфидом углерода. Показано, что давление, соответствующее максимальному содержанию эндоэдральных металлофуллеренов с иттрием, составляет $60 \mathrm{kPa}$, при этом экстракция дисульфидом углерода позволяет выделить эндоэдральный металлофуллерен в количестве $27.1 \mathrm{wt} . \%$, а экстракция пиридином - в количестве $17.3 \mathrm{wt} . \%$.
\end{abstract}

Работа выполнена при поддержке гранта Министерства образования и науки РФ (русско-японский совместный проект, соглашение № 14.613.21.0010, ID RFMEFI61314X0010).

DOI: 10.21883/FTT.2017.08.44770.394

\section{1. Введение}

В настоящее время как экспериментально, так и теоретически показано, что давление гелия, при котором проводится синтез фуллеренов, является основным параметром, влияющим как на количество образующихся фуллеренов, так и на качественный состав фуллереновой смеси $[1,2]$. Таким образом, в рамках модели образования обычных фуллеренов, учитывающей влияние электронной концентрации и отжига углеродных кластеров, влияние давления на количественный выход фуллеренов и качественный состав фуллереновой смеси хорошо объясняется [3]. Для синтеза эндоэдральных металлофуллеренов (ЭМФ) давление гелия в камере также остается наиболее существенным параметром. Однако объяснить это влияние пока не представляется возможным. В настоящее время накопленных экспериментальных результатов еще недостаточно для выработки концепций образования ЭМФ. Это связано с тем, что свойства различных ЭМФ сильно различаются [4]. Например, экстракция ЭМФ различными растворителями приводит к разным количественным результатам. Кластерная природа растворимости также затрудняет процесс разделения на индивидуальные фракции. В соответствии с отмеченным выше, неизбежны потери, связанные с переводом вещества из раствора в одном растворителе в раствор в другом растворителе и частичной необратимой сорбцией его на сорбенте. Обычно фуллерены растворяют в толуоле и растворы подвергаются хрома- тографическому разделению с последующим анализом выделенных фракций. Этот метод приводит к затруднению получения адекватной оценки влияния параметров синтеза на образование ЭМФ. Мы сумели избежать этих трудностей и провели исследования влияния давления на синтез ЭМФ с Ү в плазме высокочастотной (ВЧ) дуги.

В работе нами использовались методы масс-спектрального анализа, рентгеновской фотоэлектронной спектроскопии (РФЭС), высокоэффективной жидкостной хроматографии и атомно-эмиссионной спектроскопии, комплексное применение которых позволило однозначно установить количественное содержание ЭМФ в углеродных конденсатах (УК), полученных при разных давлениях. Также мы приводим результаты, свидетельствующие об эффективности выделения фуллереновых экстрактов из УК, полученных при введении $\mathrm{Y}_{2} \mathrm{O}_{3}$, по технологии Сокслета пиридином и дисульфидом углерода.

\section{2. Эксперимент}

Синтез УК, содержащего фуллерены и ЭМФ, осуществлялся в дуговом разряде переменного тока частотой $60 \mathrm{kHz}$ на установке, описанной нами ранее [5]. Применение переменного тока не приводит к образованию катодного депозита, соответственно конверсия материала электродов в содержащий фуллерены УК происходит наиболее полно и составляет величину, 
близкую к $100 \%$. Для дуги ВЧ-тока характерно отсутствие быстрого „сбегания“ катодных электродных пятен в одно большое пятно. Поэтому материал электродов равномерно испаряется даже при высоких значениях тока дуги и высоких давлениях, а не крошится под действием больших градиентов температуры [5].

УК был получен в результате распыления стержней для атомно-эмиссионного спектрального анализа (ТУ 3497-001-51046676-2008) с осевыми отверстиями, диаметром $3 \mathrm{~mm}$ и длиной $85 \mathrm{~mm}$. Осевые отверстия были заполнены смесью графитового порошка и $\mathrm{Y}_{2} \mathrm{O}_{3}$ (ОСТ 48-208-81) в массовом соотношении $1: 1$. Стержни отжигались в вакууме при температуре $1800^{\circ} \mathrm{C}$ и закреплялись в охлаждаемых водой держателях, находящихся в герметичной камере, также охлаждаемой водой. Синтез проводился в диапазоне давлений гелия $33-360 \mathrm{kPa}$. Стержни подавались непрерывно в процессе их выгорания таким образом, чтобы ток дуги оставался постоянным. Скорость подачи гелия поддерживалась в пределах $41 / \mathrm{min}$, а изменение давления в камере не превышало $2-3 \%$ от заданного. Образовавшийся УК делили на две равные части. Извлечение ЭМФ из УК проводилось методом экстракции в аппарате Сокслета. Одна часть экстрагировалась пиридином, а другая дисульфидом углерода. На основе полученных результатов по разработанной нами методике [6] производился расчет количества образовавшихся ЭМФ.

\section{3. Результаты и обсуждение}

Как следует из анализа литературных данных, для выделения каждого вида ЭМФ необходимо использовать определенный растворитель [7]. Наиболее универсальным растворителем можно считать дисульфид углерода, однако он может привнести в фуллереновый экстракт нежелательные для дальнейших исследований примеси

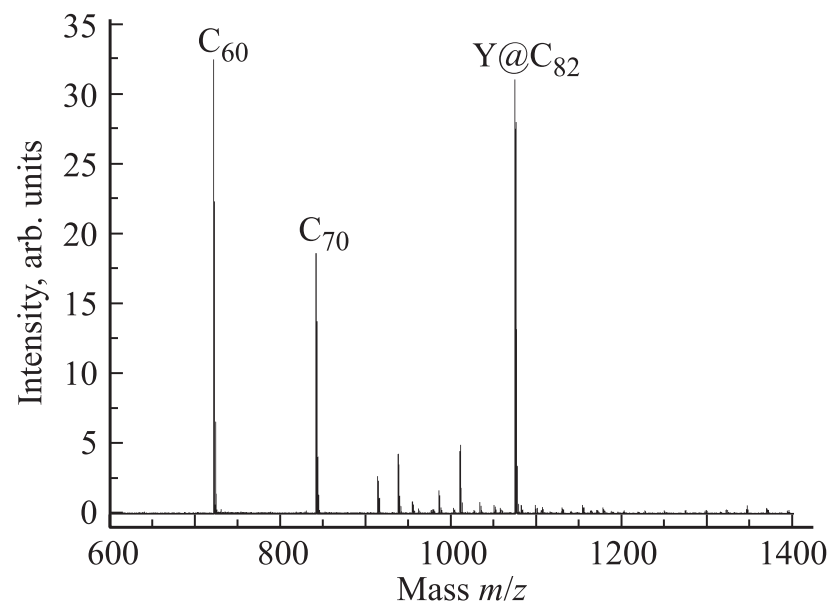

Рис. 1. Масс-спектр (MALDI-TOF Bruker BIFLEX TM III) экстрагированных пиридином фуллеренов, полученных с введением $\mathrm{Y}_{2} \mathrm{O}_{3}$ при давлении $360 \mathrm{kPa}$ (положительная мода).
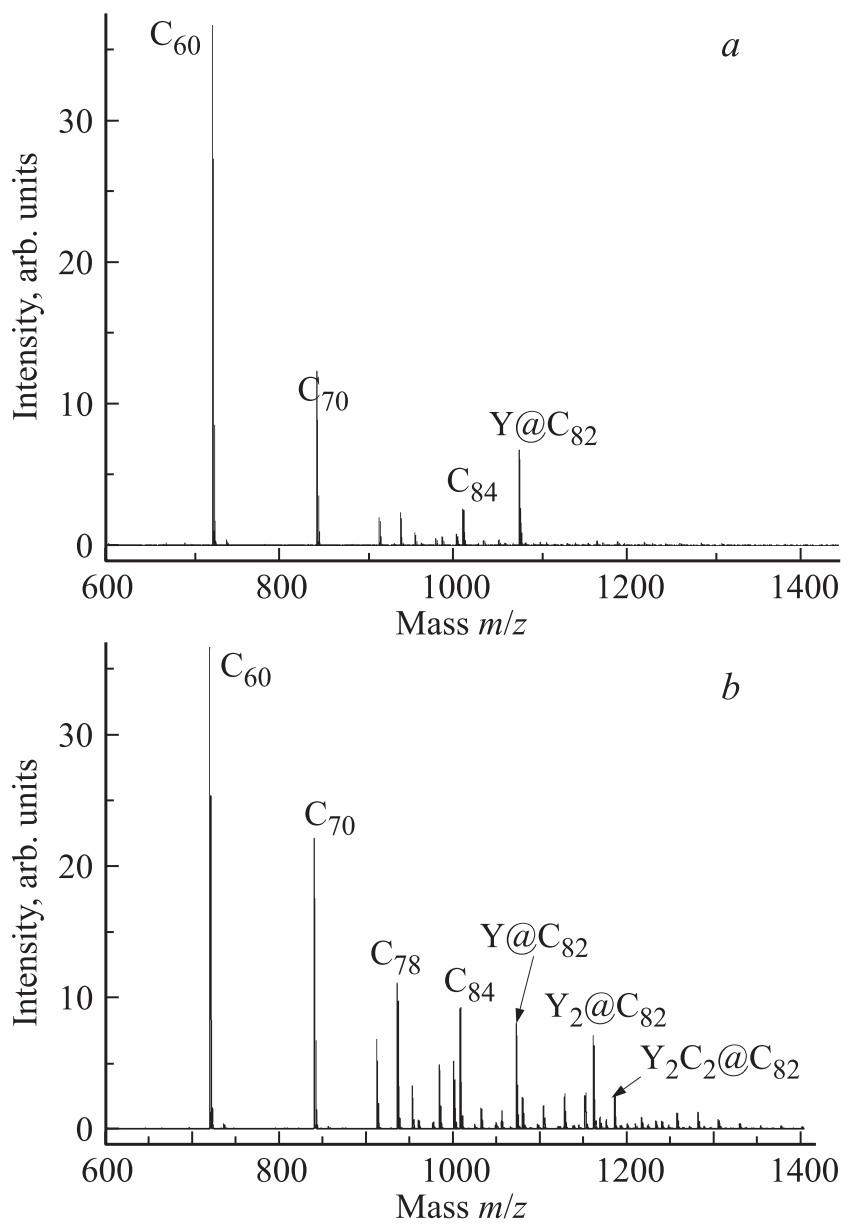

Рис. 2. Масс-спектры фуллеренового экстракта, выделенного из УК, полученного при введении $\mathrm{Y}_{2} \mathrm{O}_{3}$ при давлении $60 \mathrm{kPa}$, пиридином (положительная мода) ( $a$ ) и дисульфидом углерода (положительная мода) $(b)$.

серы. Тем не менее металлофуллерены, содержащие более одного атома-гостя в углеродном каркасе, наиболее эффективно экстрагируются именно этим растворителем. ЭМФ, выделенные пиридином, плохо перерастворяются в толуоле, так как остается нерастворимый осадок, обогащенный ЭМФ [8]. Нами при синтезе фуллеренов с добавлением $\mathrm{Gd}_{2} \mathrm{O}_{3}$ (давление $98 \mathrm{kPa}$, ток $190 \mathrm{~A}$ ) было показано, что содержание $\mathrm{Gd} @ \mathrm{C}_{82}$ в пиридиновом экстракте составило $2.9 \mathrm{wt} . \%$, а при перерастворении в толуоле было обнаружено всего лишь 1.0 wt.\% и в нерастворимом в толуоле осадке $7.1 \mathrm{wt} . \%$ [9].

Было установлено, что ЭМФ, в молекуле которых содержится один атом-гость, лучше выделять пиридином (рис. 1), а содержащие более одного атома-гостя дисульфидом углерода. Так, экстракция пиридином из одной части УК позволила хорошо экстрагировать лишь ЭМФ с одним атомом металла - Ү@ $\mathrm{C}_{82}$ (рис. 2, $a$ ). Из другой части этого же УК дисульфидом углерода был выделен целый ряд ЭМФ: Ү@ $\mathrm{C}_{82}, \mathrm{Y}_{2} @ \mathrm{C}_{82}$ и $\mathrm{Y}_{2} \mathrm{C}_{2} @ \mathrm{C}_{82}$ (рис. 2, $b$ ). 

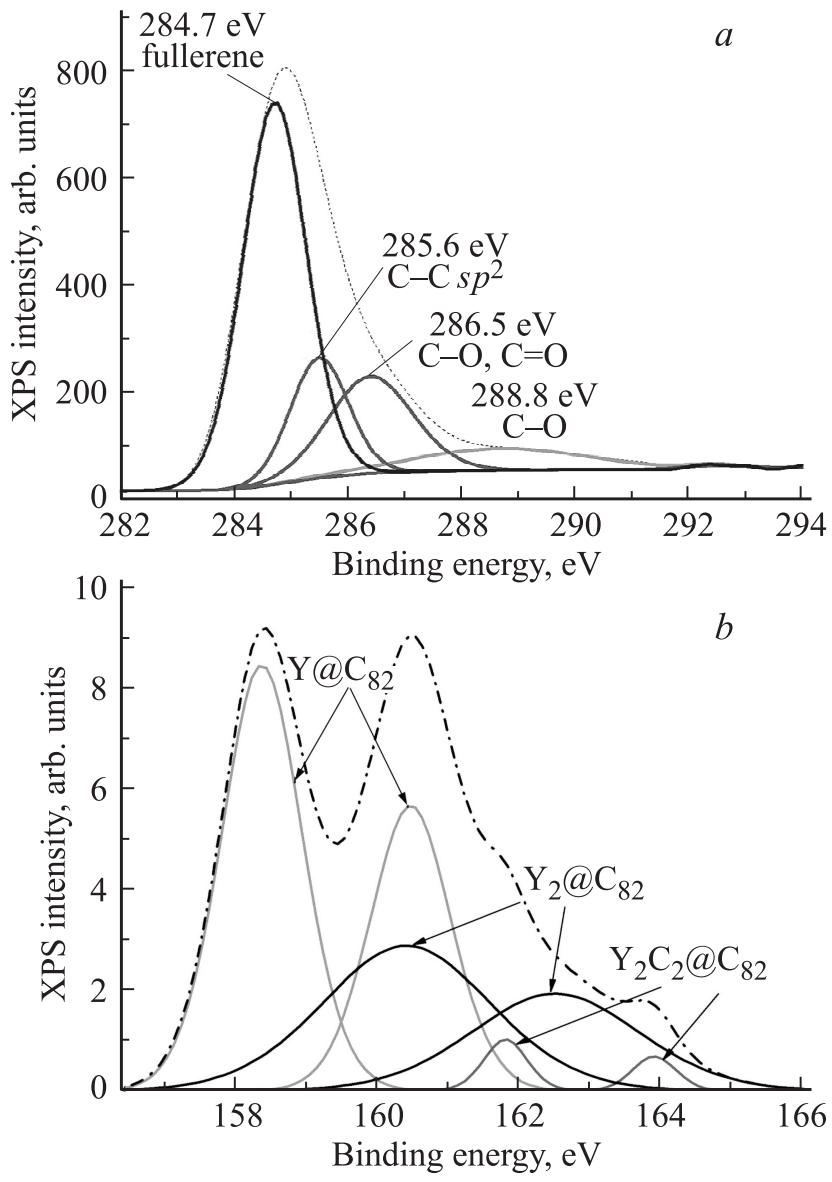

Pис. 3. РФЭС-спектр фуллеренового экстракта, полученного с введением $\mathrm{Y}_{2} \mathrm{O}_{3}$ при давлении $60 \mathrm{kPa}$ и выделенного дисульфидом углерода. $a-$ линия $\mathrm{C} 1 s, b-$ линия $\mathrm{Y} 3 d$.

В соответствии с тем что высушивание с последующим повторным растворением приводит к потере ЭМФ, для количественной оценки влияния параметров синтеза на эффективность образования фуллеренов мы исследовали фуллереновые экстракты без повторного растворения. Методом атомно-эмиссионной спектроскопии [7] мы проанализировали фуллереновый экстракт, масс-спектр которого приведен на рис. $2, b$, и получили, что содержание Y в нем составило $4.5 \mathrm{wt} \%$. Анализ образца методом РФЭС (спектрометр UNI-SPECS (SPECS)) показал, что содержание Y в образце составляет 4.1 wt.\%.

В фотоэлектронном спектре фуллеренового экстракта, полученного с введением $\mathrm{Y}_{2} \mathrm{O}_{3}$ при давлении $60 \mathrm{kPa}$ и выделенного дисульфидом углерода, Gaussian/Lorentzian-разложение линии C $1 s$ (рис. 3,a) позволяет выделить компоненты, отвечающие энергии связи $E_{b}=284.7 \mathrm{eV}-$ фуллерен, $E_{b}=285.6 \mathrm{eV}$ $s p^{2}$-гибридизация С $(56.4$ и $16.1 \%$ от площади линии $\mathrm{C} 1 s$ соответственно), $E_{b}=286.5 \mathrm{eV}-\mathrm{C}-\mathrm{O}-$ и $\mathrm{C}=\mathrm{O}(19 \%$ от площади линии $\mathrm{C} 1 s), E_{b}=288.8 \mathrm{eV}-$ $\mathrm{C}-\mathrm{O}(8.5 \%$ от площади линии $\mathrm{C} 1 s)$. Первоначально было обнаружено, что Y, связанный с фуллереном, находится в трех состояниях, характеризующихся тремя дублетами, полученными при Gaussian/Lorentzianразложении линии Ү $3 d$ (рис. $3, b$ ). После травления ионами $\mathrm{Ar}$ в течение $3 \mathrm{~min}(1 \mathrm{kV}$, ток $10 \mu \mathrm{A})$ наблюдался уже только один дублет, соответствующий $\mathrm{Y} @ \mathrm{C}_{82}$. Таким образом, соединение Y@ $\mathrm{C}_{82}$ наиболее устойчиво по отношению к внешним воздействиям. Выделенные компоненты линии $\mathrm{Y} 3 d_{5 / 2}$ соответствуют $[10] E_{b}=158.3 \mathrm{eV}-\mathrm{Y} @ \mathrm{C}_{82}$ (56\% от площади линии $\left.\mathrm{Y} 3 d_{5 / 2}\right), E_{b}=160.4 \mathrm{eV}-\mathrm{Y}_{2} @ \mathrm{C}_{82}(40 \%$ от площади линии $\left.\mathrm{Y} 3 d_{5 / 2}\right), E_{b}=161.8 \mathrm{eV}-\mathrm{Y}_{2} \mathrm{C}_{2} @ \mathrm{C}_{82}$ (4\% от площади линии $\left.\mathrm{Y} 3 d_{5 / 2}\right)$ и подтверждают масс-спектральные исследования (рис. $3, b$ ). Из [11] следует, что нахождение димера $\mathrm{Y}_{2}$ внутри молекулы может приводить к существенной деформации каркаса атомов $\mathrm{C}_{82}$.

Если из масс-спектральных исследований известно, что металл находится только в структуре ЭМФ, то методом РФЭС на основе энергий связи мы однозначно определяем количество образовавшихся ЭМФ при данных параметрах синтеза. Также на основе масс-спектральных исследований и количественного содержания металла в фуллереновом экстракте мы качественно можем оценить эффективность синтеза. Так, на основании проведенных исследований было рассчитано, что при давлении гелия в камере, равном $360 \mathrm{kPa}$, содержание иттрия в фуллереновом экстракте составляло $4.4 \mathrm{wt} . \%$, при $230 \mathrm{kPa}$ - 5.5 wt.\%, при $120 \mathrm{kPa}-6.9$ wt.\%, при $60 \mathrm{kPa}-11.4$ wt.\%, при $30 \mathrm{kPa}-11.3$ wt.\%.

\section{4. Заключение}

Таким образом, количество ЭМФ с иттрием, содержащихся в УК, полученных в дуговом ВЧ-разряде, существенно снижается с увеличением давления гелия в камере. Тот факт, что количество образующихся высших фуллеренов с ростом давления увеличивается, а ЭМФ уменьшается, указывает на разные механизмы их образования. Оптимальным давлением, обеспечивающим максимальный выход ЭМФ с иттрием, является $60 \mathrm{kPa}$.

Показано, что применение пиридина целесообразно при экстракции ЭМФ с одним атомом внутри молекулы. Использование дисульфида углерода позволяет максимально эффективно выделять ЭМФ, содержащие более одного атома-гостя в углеродном каркасе. В случае ЭМФ с иттрием, как показали наши исследования, дисульфид углерода позволил выделить Ү@ $\mathrm{C}_{82}, \mathrm{Y}_{2} @ \mathrm{C}_{82}$ и $\mathrm{Y}_{2} \mathrm{C}_{2} @ \mathrm{C}_{82}$. Как показали РФЭС-исследования, наиболее устойчивым к внешним воздействиям оказался $\mathrm{Y} @ \mathrm{C}_{82}$.

\section{Список литературы}

[1] Д.В. Афанасьев, А.А. Богданов, Г.А. Дюжев, А.А. Кругликов. ЖТФ 67, 2, 125 (1997).

[2] Y. Saito, M. Inagaki, H. Shinohara, H. Nagashima, M. Ohkohchi, Y. Ando. Chem. Phys. Lett. 200, 643 (1992). 
[3] G.N. Churilov, A.S. Fedorov, P.V. Novikov. Carbon 41, 173 (2003).

[4] A.A. Popov, S.F. Yang, L. Dunsch. Chem. Rev. 113, 5989 (2013).

[5] G.N. Churilov, W. Kratschmer, I.V. Osipova, G.A. Glushenko, N.G. Vnukova, A.L. Kolonenko, A.I. Dudnik. Carbon 62, 389 (2013).

[6] G.N. Churilov, A.A. Popov, U.E. Guliaeva, N.A. Samoylova, N.G. Vnukova, A.L. Kolonenko, V.G. Isakova, A.I. Dudnik, V.S. Koravanets. Nanosystems: physics, chemistry, mathematics 7, 140 (2016).

[7] В.С. Козлов, М.В. Суясова, В.Т. Лебедев. ЖПХ 87, 137 (2014).

[8] М.В. Авдеев, В.Л. Аксенов, Т.В. Тропин. ЖФХ 84, 1405 (2010).

[9] Г.Н. Чурилов, А.А. Попов, Н.Г. Внукова, А.И. Дудник, Г.А. Глущенко, Н.А. Самойлова, И.А. Дубинина, У.Е. Гуляева. Письма в ЖТФ 42, 9, 64 (2016).

[10] C. Ton-That, A.G. Shard, V.R. Dhanak, H. Shinohara, J.S. Bendall, M.E. Welland. Phys. Rev. B 73, 205406 (2006).

[11] Z. Wang, R. Kitaura, Y. Shinohara. J. Phys. Chem. C 118, 13953 (2014). 